\title{
Booming Medical Tourism and Economic Indices
}

\author{
Ramalingam Shanmugam
}

School of Health Administration, Texas State University, San Marcos, TX78666, USA

\begin{abstract}
Globalization in this 21 st century unifies nations. The globalization impacts positively to promote trade and services among the nations but it could also harm economic growth and technological innovations in nations as their capital are drained to elsewhere. On its own merits, the globalization is a true manifestation of an open economy. The medical profession is not immune to this phenomenon: globalization. Mainly for the sake of affordability, many patients in much advanced nations, often voluntarily, seek medical services in far less underdeveloped nations. In other times, some patients are incited by their health insurance industries to practice medical tourism. The medical tourism creates an economic turmoil. Several medical economists are quite puzzled by the advantages as much as by the damaging impacts by the booming popularity of the medical tourism. It is time that all consequences of the medical tourism are examined in details as the findings would benefit the patients, the health policy makers and health industries. Such are the aims of this article. This article applies a data mining approach to compute and interpret economic indices, in a novel manner, to portray the economic booming in the hosting nations which render the medical treatments to the patients who emanate from the guest nations. Using the variations in the medical tourism data, a principal components analysis is performed to group the medical treatments and separately to group the hosting nations in terms of their closer proximities. According to the principal component analysis of the medical tourism data, there are three groups of nations which provide the treatments. The first group consists of USA, Columbia, Costa Rica and Nicaragua. The second group consists of India, Israel and South Africa. The third group consists of Jordan, Thailand and Malaysia. Also, an analysis of variance is performed to assess the significance of the factors on the cost of the medical treatment. Performing likewise on the type of the medical treatments which the medical tourists seek, there are three groups. The first group consists of medical treatments: heart by-pass, angioplasty, heart valve replacement, hip replacement, hip resurfacing, knee replacement, spinal fusion, gastric sleeve and gastric by-pass and lap band and liposuction and ivy treatments. The second group consists of tummy tuck, breast implants, rhinoplasty, facelift, hysterectomy, cornea and retina. The third group consists of dental implant and Lasik eyesurgery. The analysis of variance reveals that the nation Israel differs significantly from the hosting nations Columbia, India, Jordan, Malaysia and South Africa. The nation India differs significantly from the hosting nations South Korea. Furthermore, the Gini's index of heterogenity and entropy index of heterogenity are computed as these indices capture the cost data volatility. These indices are then standardized and interpreted. Among the nations from which the medical tourists seek treatment in other nations, the nation USA emerges to the top in the list while Israel, India, South Korea and Thailand are emerging to the top in the list for treatments by the medical tourists. Interestingly, the cost differences among all other nations are not significantly different. The medical tourists concentrated on nations: India, Malaysia, Columbia and Mexico in its descending order of importance for the medical treatments: heart bupass, ental impant and liposuction in its descending order.
\end{abstract}

Key words: Concentration Index, Proximity of Medical Treatments, Information Theory, P-Value 


\section{INTRODUCTION}

What is medical tourism? It is a blending of pleasure tour with a medical treatment in a hospital/clinic setting during the vacation period. The destination place in the medical tour for a medical service is defined in this article as the hosting nation. The place from which the patients come is called the guest nation in this article. The medical tourism could take place inside within the nation but often happens outside in a foreign nation (Hopkins et al., 2012). A patient crosses the international borders only to receive an affordable or better quality medical care to recover from an illness (Johnston et al., 2010; Turner, 2010). The medical tourism to a place far away from the residential location becomes a necessity for several conveniences in the distant place.

For an example of the conveniences, a liver transplant costs about $\$ 300,000$ in USA on the average even without including any travel expense to the location for the US residents while it is only $\$ 91,000$ in a hosting nation which includes air travel, luxurious hotel accommodation and exotic vacation pleasure tours for the family including the patients.

Another example is the heart valve replacement and it costs about $\$ 200,000$ for the residents in USA on the average excluding any travel cost within the nation while it is only $\$ 10,000$ in the hosting nation India (Malchesky,
2011) which includes airfare, star hotel accommodation charge and sight-seeing vacation tour expenses. A medical treatment in a hosting nation is resorted not only for shear monetary advantages to the budget-minded patients but also for keeping down the health insurance premiums to the health insurance policy holders in the insurance companies. In fact, in some instances, the health insurance companies reimburse the patient's airline ticket and lodging expenses to encourage that a medical procedure for their client is done in a hosting nation for the sake of lowering the overall healthcare payment. Also, the governments of the hosting nations create incentives or attractive travel packages for the incoming medical tourists. In this uneven economic background among the hosting versus guest nations, the medical tourism booms in the $21 \mathrm{st}$ century. This booming phenomenon triggers economic frictions at times between the hosting and guest nations. The discussion of frictions and ranking of the hosting nations is the theme of this article. Reasons for a lower healthcare cost in the hosting nations include subsidiaries by their governments. Also, included but are not limited to be higher salary for the physician, nurse and support labor, an inflated pharmacy cost and the fear of malpractice suit and its impact on high premium treatment cost in the guest nations.

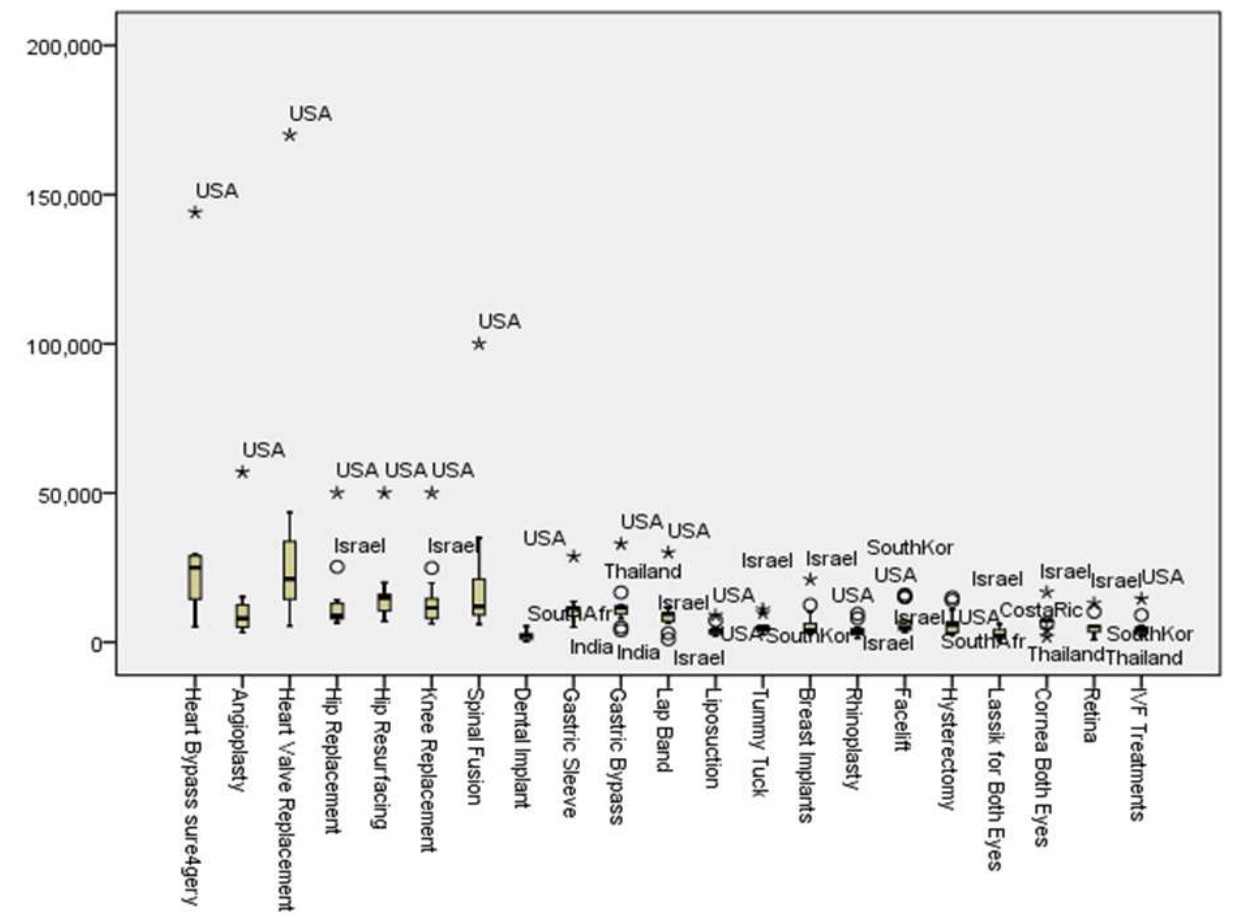

Fig. 1. Box plots for the costs of 21 treatments 
Another reason for the booming medical tourism is a longer waiting time for some medical treatments in the guest nations. For an example for the longer waiting time, note that about 782,936 Canadians wait on the average of 26 weeks for a hip replacement and 16 weeks for a cataract surgery. The waiting times are much less in several hosting nations including Israel. Hence, the 21 st century experiences a precedented but inevitable worldwide economic conflicts and collisions due to the globalization (Turner, 2010). The healthcare field is no exception to the globalized competitions. Truly, the economic frictions exhibit paradoxes. Mostly, the hosting nations are under-developed compared to the guest nations of the patients. In this borderless healthcare business, several non-measurable economic repercussions exist. The hosting nations' economic growth helps to import advanced medical instruments and experts. The medical technologic growth booms at an astonishing rate in the hosting nations. The international trade imbalance of payments also results in. The guest nations of the medical tourists are mostly developed but struggle to balance their budget, to pay their internal and external payments as their sluggish economic slum continues and the medical tourism makes its own share to such crisis (Samir and Karim, 2011). Several health and other economists ponder over a question: Does the medical tourism result in a zero-sum economic growth with no easy resolution? Strangely, the hosting nations are unable to tackle their own healthcare issues for their own citizens but paradoxically attempt to take care of the foreign patients' healthcare. The configurations in Fig. 1 provide clues to the importance of performing data mining.

However the truth exists in such scenarios, the core problem of the healthcare oriented economic issues seems to be affordability for the health insurance companies as much as to the patients. The affordability issue has turned upside down the healthcare industries in both the hosting and guest nations. An administrative setback in the globalized healthcare business is its unregulated operation style in the hosting nations (Niechajev and Frame, 2012). Consequently, the outsourcing of the medical care needs to examine the legal complications for the hosting as much as to the guest nations to deal with the authentic versus fraudulent healthcare accusations by the incoming foreign patients. Nevertheless, does the influx of foreign patients to the local hospitals precipitate a neglect of guest patients in the hosting nation causing a secondary importance to the healthcare of the local patients in the hosting nations?

Now, we ask: what do the pertinent worldwide healthcare medical tourism data reveal? A major impediment to comprehend the consequences of the medical tourism data is the lack of more authentic data in a public domain. For the sake of the patient's confidentiality and the organizational privacy to protect details from the competitors, the data and their details about the medical treatment cost to the medical tourists, how many and how long the foreign patients stayed in their hospitals are kept confidential and secretive from the outsiders. In other words, the source for the medical tourism data is scarce. Nevertheless, a cost analysis based on an available data is necessary and it is performed in this article with the data mining tools Giudici and Figini, (2009) for details on data mining tools. Also, examined are the imprints of the medical tourism on the worldwide economy. The data mining works out wonderfully to extract many hidden implications and also interpret the pertinent information as done in this article.

\subsection{How to Mine Medical Tourism Data}

The importance of data mining concepts and their tools to discover the patterns in the medical tourism data are first introduced. What is data mining? Analogous to how geologic engineers mine the ground to discover precious diamond deposits; the multivariate exploratory methods which help to uncover the patterns in the data are called data mining. The data mining is popularly practiced in computer and electronic disciplines. The health discipline is now noticing the importance of the data mining methods.

We consider the treatment cost from the open domain online webpages. See the medical tourism cost data for various procedures in several nations in Table 1. This data considered in this article consists of the costs for twenty-one medical treatments and they are: heart bypass, angioplasty, heart valve replacement, hip replacement, hip resurfacing, knee replacement, spinal fusion, dental implant, gastric sleeve, gastric by-pass, lap band, liposuction, tummy tuck, breast implants, rhinoplasty, facelift, hysterectomy, Lasik eye-surgery, cornea, retina, ivy treatment in thirteen hosting nations. The hosting nations are: USA, Columbia, Costa Rica, India, Jordan, South Korea, Mexico, Israel, Thailand, Vietnam, South Africa, Malaysia and Nicaragua. First methodology in the data mining is "Box-Whiuskar" plot which give clue whether the data are symmetric and normal type. When there are outliers in the data, they would fall either above the location of 1.5 times the Semi-Inter-Quartile Range (SIQR) from the 75th percentile or below the level of 1.5 times the SIQR from the 25 th percentile. The lower, middle and upper line in the middle box denote respectively the $25 \mathrm{th}, 50 \mathrm{th}$ and 75 th percentiles. The one half of the gap between the 25 th and 75th percentiles is the SIQR. When the spread between the largest observation (excluding the high 
outliers) and the 50th percentile is same as the spread between the 50th percentile and the lowest observation (excluding the low outliers), the data are normally distributed. Furthermore, when the area of the box between the 25 th and 50 th percentiles is equal to the area between the 5 oth and 75 th percentiles, the data are considered symmetric with no skewness. When the data are normally distributed, the data are suitable for hypothesis testing in the data mining methodology.

Let us now look at the clues in the data. Notice that USA emerges to get the first rank among the guest nations in the medical tourism while Israel, India, South Korea and Thailand are emerging to the top in the list for medical tourists. Not all the hospitals in these hosting nations are accredited. The Joint Commission International (JCI) accredited only 11, 6, 2 and 2 hospitals in Singapore, India, Thailand and Taiwan respectively. NaRanong and NaRanong (2011) for Thailand's experience with the medical tourists. An elaborate discussion about the disadvantages of unregulated globalized medical treatment is worthwhile and should be done to inform the medical tourists.

The hosting nations differ in their jurisdiction of maintaining high standards. The guest nations could not exert influence on the hosting nations to improve service standard for the medical tourists. Some hospitals in the hosting nations might even be health hazardous to the medical tourists. Attending physicians or medical interns work in the procedures outside their expertise and the medical tourists in the hosting nations are even unaware of this. Also, uncertified medical researchers work temporarily in the hosting nations' hospitals with an expectation to obtain permanent future work in resource-starved sub disciplines (Jose and Sachdeva, 2010). These problems add up to an increasing risk for the medical tourists (Mason and Wright, 2011).

The risks to the medical tourists are unhygienic hospital infections, virus environment to pick up other diseases such as hepatitis, malaria or tuberculosis. The tiresome long international travel time ignites more risk among some medical tourists to develop weaker heart condition (Solomon, 2011). A major disadvantage occurs during the post-treatment period after returning from the hosting nation. During that time, the personal care physician in the guest nation is unfamiliar or unable to effectively post-deal with the delayed infection and complications (Garg, 2013).

In lieu of limited or no local litigation law, no compensation or lawsuit becomes a possibility for the medical tourists. Such ethical issues are nightmares in some cases. For an example, illegal organ purchases or medical products that are manufactured by the prisoners in the hosting nations could disturb the peace and conscious mind of the medical tourists. No strict laws like Health Insurance Portability and Accountability Act (HIPPA) in USA now exist in the hosting nations to protect the privacy of the medical tourists. Also, the guest nations lose incentives or resources to conduct clinical trials to discover new, better treatments as the patients' drainage to the hosting nations occur while the hosting nations are not enthusiastic to advance the medical knowledge. Medical research advancements take a backseat or are disabled to an alarming level so that much needed and desperate medical breakthroughs are not within reach. But, the open market principle of supply versus demand works conductively in healthcare services as well and it will eventually resolve the economic conflicts and collisions due to globalized medical tourism. Data supported evidence to these and related issues could not be done though the data mining is quite capable once the pertinent data are collected and made available for the researchers. As of now with the limited data, there are more questions than the answers. The questions are listed below and they need further scrutiny:

- Do the guest nations have more incidence rate of illness or treatment needs than what the hosting nations can provide

- How much does the globalized healthcare help the hosting nations to grow their economy or increase their employment rate? Are these at the cost of growth in the guest nations? Is it resulting in a zerosum economic game

- Should the healthcare become a patriotic entity? Should the healthcare consumption of service be closer to the patient's place? Should export tariffs or quotas be imposed in the healthcare medical tourism as well to compensate the depleting local economy? Isn't the economy a by-product of the local people based on their activities?

- Are the medical treatments in the guest nations becoming non-affordable while affordable in the hosting nations? What factors could tilt the balance? Do the factors include inefficient governing style in the guest nations or more efficiency in hosting nation

- Are the guest nations more polarized while the hosting nations more harmonious in the globalized healthcare operations

- Is there a disparity in the promotion of healthcare consumerism between the hosting and the guest nations to attain human happiness

- Is the population growth an obstacle or added resource in healthcare

- Is the advanced status of a guest nation an ironic liability to healthcare non affordability 
- Does the globalized healthcare hurt or help in the hosting as much as the guest nations

- A misconception is that the hosting nations are cheaper than the guest nations in healthcare services. For examples, the dental implanting costs more in South Korea or South Africa compared to USA, the breast implant costs more in Israel or South Korea than in USA. The treatment of retina costs more in Israel or Jordan than in USA

The answers to the above questions will turn out with data we don't have, the available cost data trends in the medical tourism are asymmetric and skewed in nonnormal type as revealed by their stem-and-leaf plots of the data in Table 1. Further data mining reveals that the costs appear to gamma distributed.

However, a Principal Component (PC) analysis of the medical tourist's costs in Table $\mathbf{1}$ is worthwhile. What is principal component analysis? It is a data reduction technique to group the variables in accordance with their close proximity of importance. There are three significant PCs (Fig. 2) accounting about $90.4 \%$ of the total variations in the data of Table $\mathbf{1}$.
The first PC groups heart by-pass, angioplasty, heart valve replacement, hip replacement, hip resurfacing, knee replacement, spinal fusion, gastric sleeve, gastric by-pass, lap band, liposuction and ivy treatments. The second PC groups tummy tuck, breast implants, rhinoplasty, facelift, hysterectomy, cornea and retina. The third PC groups dental implant and Lasik eye-surgery.

How do the hosting nations compare with each other? The first three PCs capture $89.5 \%$ of the cost variations (Fig. 3). The first PC groups USA, Columbia, Costa Rica and Nicaragua. The second PC groups India, Israel and South Africa. The third PC groups Jordan, Thailand and Malaysia as the last group of nations. Further data mining reveals that the treatments are costly in USA followed by South Korea and Israel while least expensive in India proceeded by Jordan. Consistently, the USA exhibits largest amount of variation in treatment costs. These identifications become possible with the help of principal component analysis.

Having witnessed the cost disparities for the medical tourists, it is appropriate to perform a statistical analysis using a linear model. What is linear model? The model is an abstraction of the reality.

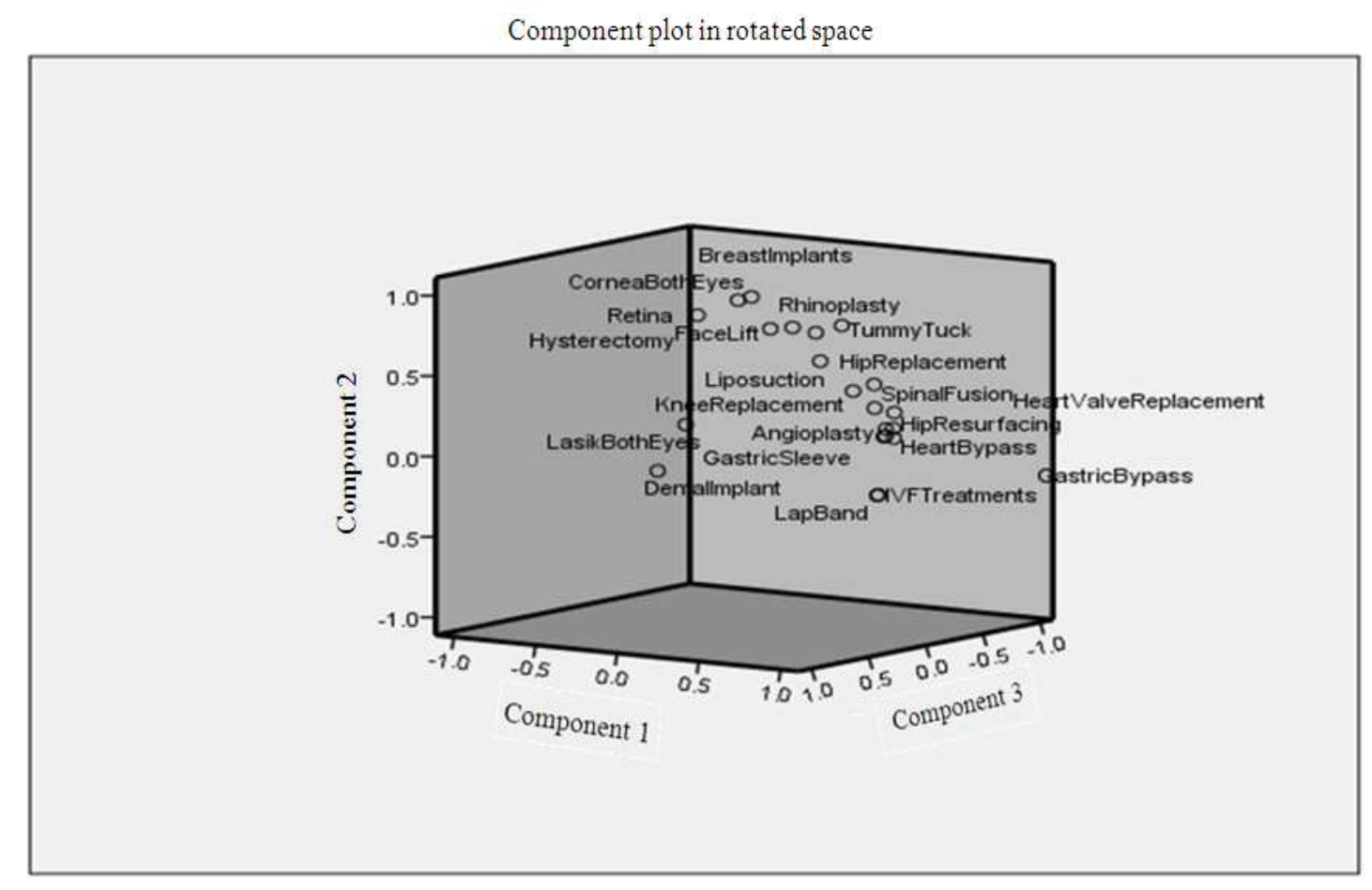

Fig. 2. Grouping treatments of medical tourists 


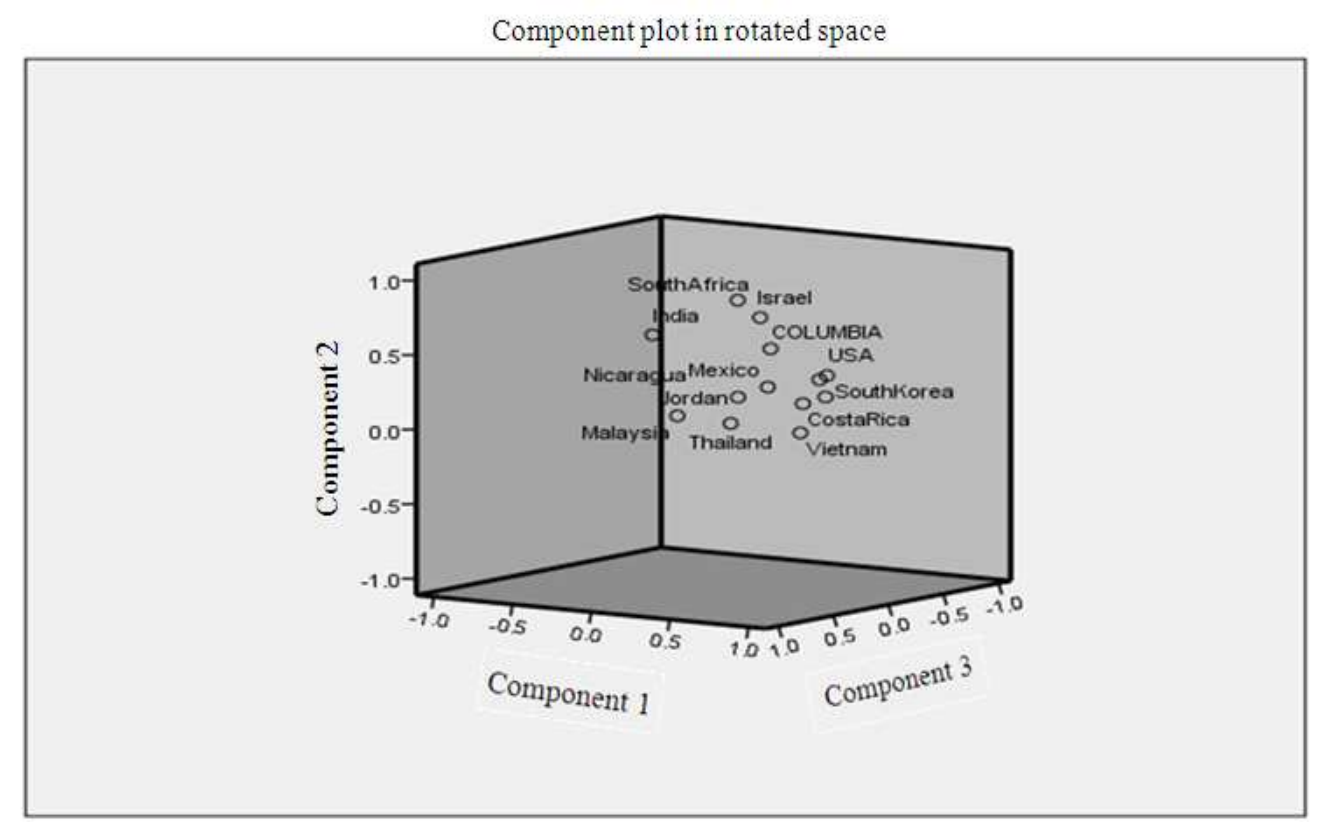

Fig. 3. Grouping hosting nations of medical tourists

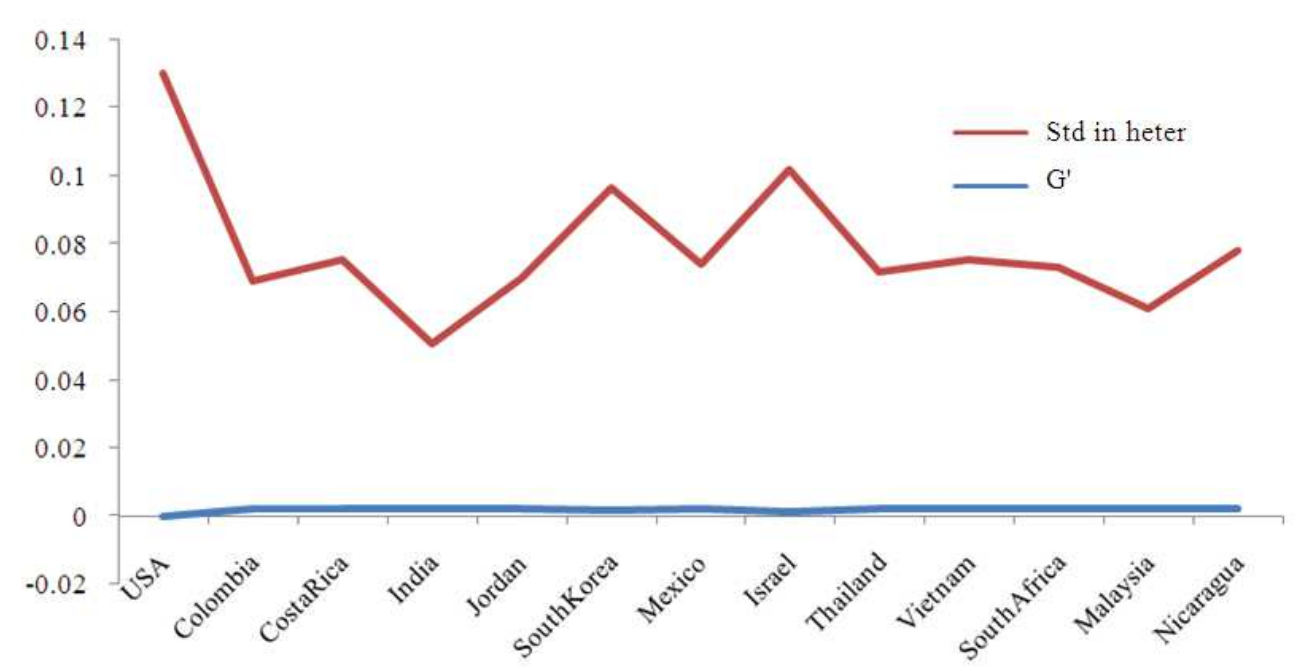

Fig. 4. Heterogenity indices of hosting nations

The linear model is a way to capture and assess the impacts of factors using the observed data. Let $\mathrm{Y}_{\mathrm{ij}}$ be the cost for $\mathrm{j}^{\text {th }}$ treatment in the $\mathrm{i}^{\text {th }}$ nation. A linear model for the cost analysis is:

$$
\begin{gathered}
Y_{i j}=\mu+N_{i}+T_{j}+\varepsilon_{i j} ; \\
i=1,2, \ldots, 13, j=1,2, \ldots 21
\end{gathered}
$$

where, the notations $\mathrm{N}_{\mathrm{i}} \varepsilon_{\mathrm{ij}}$ and $\mathrm{T}_{\mathrm{j}}$ denote the impact of the hosting nation, extraneous influence and the treatment's effect on medical tourism. The analysis of variance of the data in Table 1 reveals, based on the linear model that the cost among the hosting nations differ significantly as much as the costs among the treatments because their test scores are $F_{20,240}=6.33$ and $F_{12,240}=$ 11.12 with p-values are about 0.0001 : 


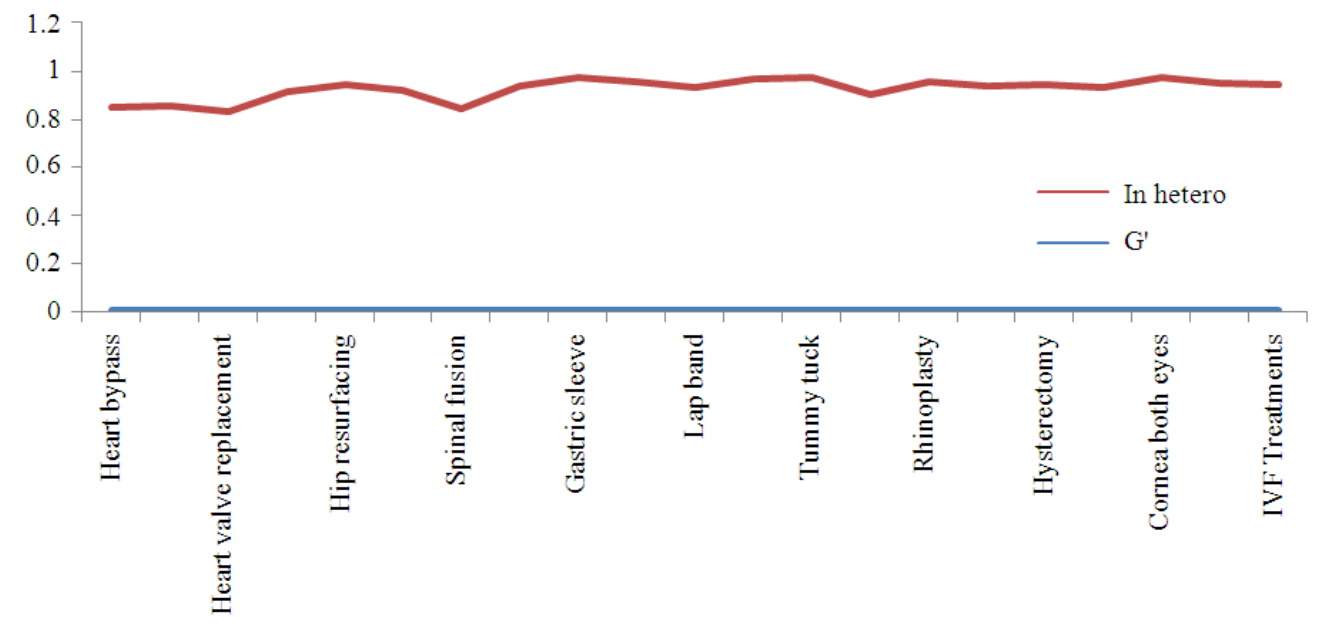

Fig. 5. Heterogenity indices of treatments of medical tourists

Table 1. Comparative cost of the medical treatments in several countries

\begin{tabular}{|c|c|c|c|c|c|c|c|c|c|c|c|c|c|}
\hline Nation & USA & Colombia & Costarica & India & Jordan & Southkorea & Mexico & Israel & Thailand & Vietnam & SouthAfric & Malaysia & Nicaragua \\
\hline HeartBypass & $\$ 144,000$ & $\$ 14,802$ & $\$ 25,000$ & $\$ 5,200$ & $\$ 14,400$ & $\$ 28,900$ & $\$ 27,000$ & $\$ 27,500$ & $\$ 15,121$ & 29395.73 & $\$ 10,000$ & $\$ 11,430$ & 29395.73 \\
\hline Angioplasty & $\$ 57,000$ & $\$ 4,500$ & $\$ 13,000$ & $\$ 3,300$ & $\$ 5,000$ & $\$ 15,200$ & $\$ 12,500$ & $\$ 8,000$ & $\$ 3,788$ & 12338.00 & $\$ 8,000$ & $\$ 5,430$ & 12338.00 \\
\hline Ment & $\$ 170,000$ & $\$ 18,000$ & $\$ 30,000$ & $\$ 5,500$ & $\$ 14,400$ & $\$ 43,500$ & $\$ 18,000$ & $\$ 29,712$ & $\$ 21,212$ & 33730.00 & $\$ 10,130$ & $\$ 10,580$ & 33730.00 \\
\hline Hip replacement & $\$ 50,000$ & $\$ 6,500$ & $\$ 12,500$ & $\$ 7,000$ & $\$ 8,000$ & $\$ 14,120$ & $\$ 13,000$ & $\$ 25,250$ & $\$ 7,879$ & $\$ 8,250$ & $\$ 10,840$ & $\$ 7,500$ & $\$ 8,700$ \\
\hline Hip resurfacing & $\$ 50,000$ & $\$ 10,500$ & $\$ 12,500$ & $\$ 7,000$ & $\$ 10,000$ & $\$ 15,600$ & $\$ 15,000$ & $\$ 20,000$ & $\$ 15,152$ & 15976.55 & $\$ 7,640$ & $\$ 12,350$ & 15976.55 \\
\hline Knee replacement & $\$ 50,000$ & $\$ 6,500$ & $\$ 11,500$ & $\$ 6,200$ & $\$ 8,000$ & $\$ 19,800$ & $\$ 12,000$ & $\$ 24,850$ & $\$ 12,297$ & $\$ 8,500$ & 14570 & $\$ 7,000$ & $\$ 8,200$ \\
\hline SpinalFusion & $\$ 100,000$ & 21164 & $\$ 11,500$ & $\$ 6,500$ & $\$ 10,000$ & $\$ 15,400$ & $\$ 12,000$ & $\$ 35,000$ & $\$ 9,091$ & $\$ 6,150.00$ & 14570 & $\$ 6,000$ & 21164.00 \\
\hline DentalImplant & $\$ 2,800$ & $\$ 1,750$ & $\$ 900$ & $\$ 1,000$ & $\$ 1,000$ & $\$ 4,200$ & $\$ 1,800$ & $\$ 2,150$ & $\$ 3,636$ & 2266.00 & $\$ 5,340$ & $\$ 354$ & 2266.00 \\
\hline GastricSleeve & $\$ 28,700$ & $\$ 7,200$ & $\$ 10,500$ & $\$ 5,000$ & 11477 & 11477 & $\$ 9,995$ & $\$ 11,500$ & $\$ 13,636$ & 11477.00 & $\$ 8,770$ & 11477 & $\$ 8,000$ \\
\hline GastricBypass & $\$ 32,927$ & $\$ 9,900$ & $\$ 12,500$ & $\$ 5,000$ & 12091 & 12091 & $\$ 10,950$ & $\$ 11,500$ & $\$ 16,667$ & 12091.00 & $\$ 3,935$ & $\$ 9,540$ & $\$ 8,000$ \\
\hline LapBand & $\$ 30,000$ & $\$ 9,900$ & $\$ 8,500$ & $\$ 3,000$ & $\$ 7,000$ & 9490 & $\$ 6,500$ & $\$ 1,000$ & $\$ 11,515$ & 9490.00 & 9490 & 9490 & $\$ 8,000$ \\
\hline Liposuction & $\$ 9,000$ & $\$ 2,500$ & $\$ 3,900$ & $\$ 2,800$ & $\$ 4,000$ & 4068 & $\$ 2,800$ & $\$ 7,242$ & $\$ 2,303$ & $\$ 2,850$ & $\$ 5,060$ & $\$ 2,299$ & 4068.00 \\
\hline TummyTuck & $\$ 9,750$ & $\$ 3,500$ & $\$ 5,300$ & $\$ 3,000$ & $\$ 4,000$ & 5195 & $\$ 4,025$ & $\$ 11,000$ & $\$ 5,000$ & $\$ 3,850$ & $\$ 2,530$ & 5195 & 5195.00 \\
\hline Breastimplants & $\$ 10,000$ & $\$ 2,500$ & $\$ 3,800$ & $\$ 3,500$ & $\$ 3,500$ & $\$ 12,500$ & $\$ 3,500$ & $\$ 21,000$ & $\$ 2,727$ & $\$ 3,850$ & $\$ 2,930$ & 6183 & $\$ 4,400$ \\
\hline Rhinoplasty & $\$ 8,000$ & $\$ 2,500$ & $\$ 4,500$ & $\$ 4,000$ & $\$ 3,000$ & $\$ 5,000$ & $\$ 3,500$ & $\$ 9,500$ & $\$ 3,091$ & $\$ 2,100$ & $\$ 3,935$ & $\$ 1,293$ & $\$ 2,400$ \\
\hline FaceLift & $\$ 15,000$ & $\$ 5,000$ & $\$ 6,000$ & $\$ 4,000$ & $\$ 4,400$ & $\$ 15,300$ & $\$ 4,900$ & $\$ 16,000$ & $\$ 3,697$ & $\$ 4,150$ & $\$ 4,620$ & $\$ 3,440$ & 7208.00 \\
\hline Hysterectomy & $\$ 15,000$ & 6749 & $\$ 5,700$ & $\$ 2,500$ & $\$ 6,000$ & $\$ 11,000$ & $\$ 5,800$ & $\$ 14,000$ & $\$ 2,727$ & 6749.00 & $\$ 3,270$ & $\$ 5,250$ & $\$ 3,000$ \\
\hline LasikBothEyes & $\$ 4,400$ & $\$ 2,000$ & $\$ 1,800$ & $\$ 500$ & $\$ 5,000$ & $\$ 6,000$ & $\$ 1,995$ & 2711 & $\$ 1,818$ & $\$ 1,640$ & $\$ 4,200$ & $\$ 477$ & 2711.00 \\
\hline CorneaBothEyes & 7232 & 7232 & $\$ 4,200$ & 7232 & 7232 & $\$ 7,000$ & 7232 & $\$ 16,700$ & $\$ 1,800$ & 7232.00 & $\$ 6,460$ & 7232 & 7232.00 \\
\hline Retina & 5332 & 5332 & $\$ 4,500$ & $\$ 850$ & 5332 & $\$ 10,200$ & $\$ 3,500$ & $\$ 13,000$ & $\$ 4,242$ & 5332.00 & $\$ 3,370$ & $\$ 3,000$ & 5332.00 \\
\hline IVFTreatments & $\$ 14,500$ & 5071 & $\$ 2,800$ & $\$ 3,250$ & $\$ 2,700$ & $\$ 2,180$ & $\$ 3,950$ & $\$ 2,800$ & $\$ 9,091$ & 5071.00 & $\$ 5,620$ & $\$ 3,819$ & 5071.00 \\
\hline
\end{tabular}

Also, their pair wise comparisons reveal the following: The nation Israel differs significantly from the hosting nations Columbia, India, Jordan, Malaysia and South Africa. The nation India differs significantly from the hosting nations South Korea. Interestingly, the cost differences among all other nations are not significantly different.

Further data mining of healthcare costs in Table 1 reveals several interesting facts. The costs for the medical tourists exhibit volatility also. An index of the cost heterogenity can be developed using a data mining technique based on the information measure and it captures their volatility. There are two approaches in data mining to formulate the heterogenity index (Giudici and Figini, 2009). The two indices of heterogenity are called Gini's Index of Heterogenity (GIH) and Entropy Index of Heterogenity (EIH). The GIH is computed using the formula:

$$
\mathrm{G}=\left(1-\sum_{\mathrm{i}=1}^{\mathrm{k}} \mathrm{p}_{1}^{2}\right) / \mathrm{k}(\mathrm{k}-1)
$$

where, $\mathrm{p}_{\mathrm{i}}$ is the proportion in the $\mathrm{i}^{\text {th }}$ Category among $\mathrm{k}$ Categories.

The index GIH is not sensitive to minor fluctuations. On the contrary, the EIH captures minute fluctuations and it is computed using $\mathrm{G}=-\sum_{\mathrm{i}=1}^{\mathrm{k}} \ln \mathrm{p}_{\mathrm{i}} / \ln \mathrm{k}$. 
Ramalingam Shanmugam / International Journal of Research in Nursing 3 (2) (2012) 38-47

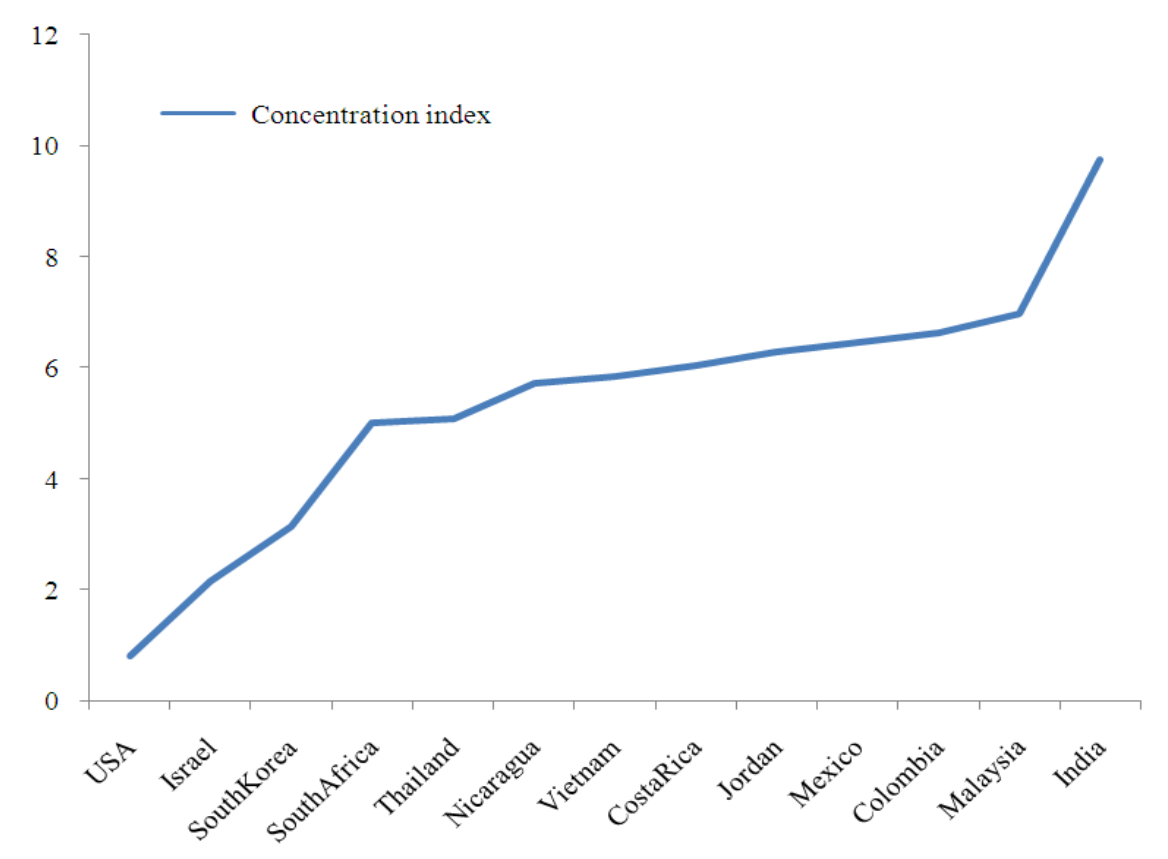

Fig. 6. Concentration index for hosting nations

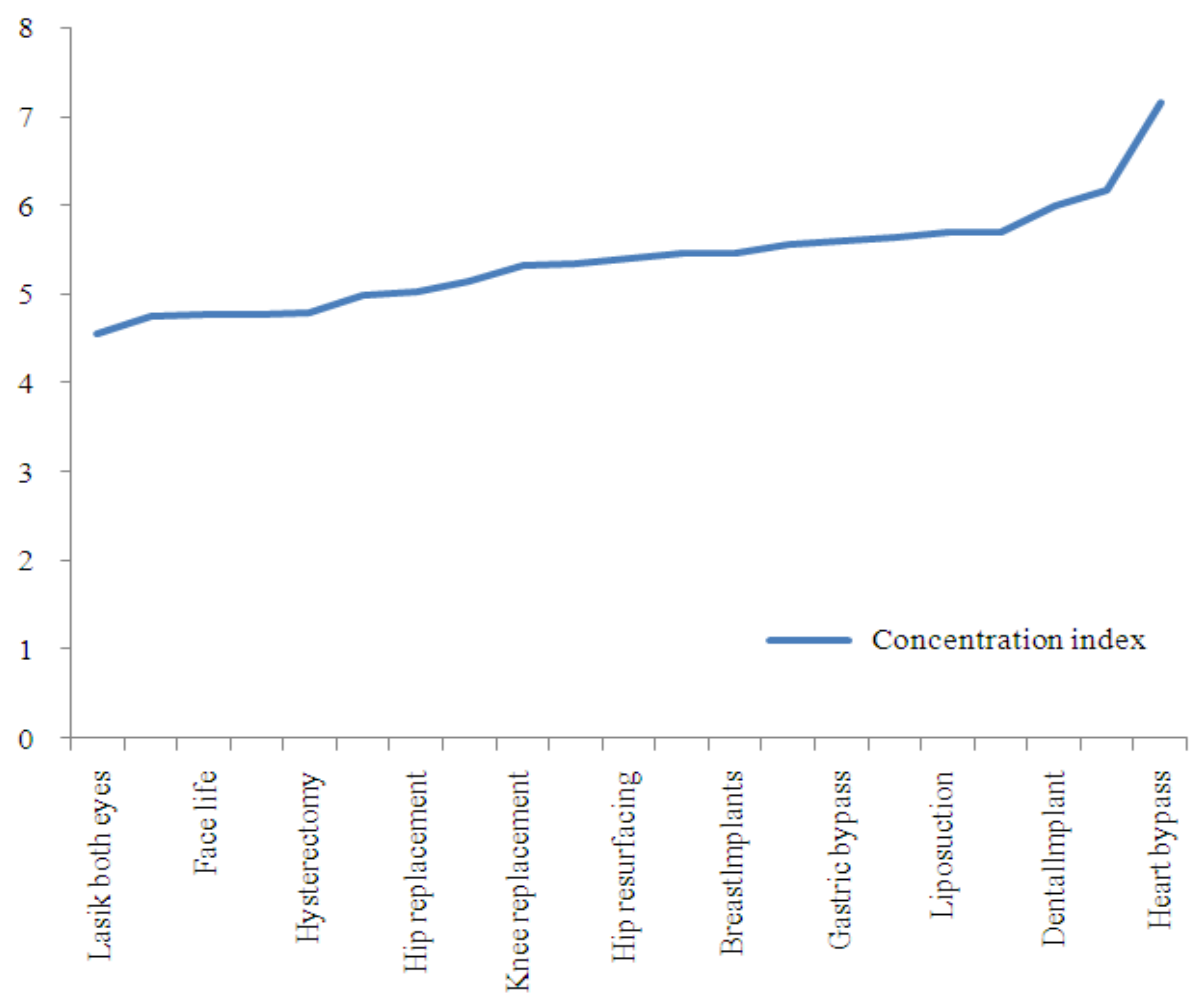

Fig. 7. Concentration index of medical treatments 
Both the indices attain value in the open interval $[0,1]$. These indices are computed and displayed for the hosting nations in Fig. 4 and for treatments in Fig. 5. According to these indices, India is the least expensive hosting nation while USA is the costlier guest nation. The heart bypass surgery and heart valve replacement do have less heterogenity compared to the other treatments. In data mining, the Gina's concentration index wraps up all pertinent informations. The Gina's concentration index is calculated using the formula $R=\frac{\sum_{i=1}^{n-1} Q_{i}}{\sum_{i=1}^{n-1} F_{i}}-1$ where $\mathrm{Q}_{\mathrm{i}}=\frac{\sum_{\mathrm{i}=1}^{\mathrm{n}-1} \mathrm{p}_{\mathrm{i}}}{\mathrm{n} \overline{\mathrm{p}}}$ and $\mathrm{F}_{\mathrm{i}}=\mathrm{i} / \mathrm{n}$ denote respectively their cumulative proportions. Recall that there are $n=13$ hosting nations and $n=21$ medical treatments in our data. The concentration indices attain value in the closed interval $[0,1]$. When the concentration index is closer to zero or one, they are interpreted respectively to possess minimal or maximal concentration. The concentration indices are graphically displayed for the hosting nations in Fig. 6 and for the medical treatments in Fig. 7. The maximum concentration occurred in nations: India, Malaysia, Columbia and Mexico in its descending order of importance. So far as the medical treatments, the maximum concentrations occurred in heart bupass, ental impant and liposuction in its descending order.

\section{CONCLUSION}

A major difficulty in generalizing or confirming the above finding is the lack of authentic abundance of medical tourism data. The medical tourism is highly competitive business. The hospitals try their best to protect their database from the competitors. However, it is worthwhile to understand the economic ramifications of the medical tourism on the hosting as well as on the guest nations.

Both the hosting and the guest nations face challenges in this era of globalized healthcare medical tourism. The hosting nations benefit with an increased revenue but experience a setback because of the neglect or low priority to provide an adequate healthcare service to their own guest patients. The guest nations experience their own citizens getting lesser expensive and affordable health services on a competitive basis but suffer with a loss of significant revenue to promote locally the health research innovations (Underwood and Makadon, 2010). Consequently, the guest nations lose competitive edge and parity in the field of health services. The remedies to these problems in either the hosting or the guest nations are not easy but are of great necessity for their economic growth and prosperity in the open competitive health research and services. The economic growth, capping the inflationary level, regulated health finance, supervised healthcare labor movements, healthcare certification, international healthcare trade, balance of healthcare payments in the foreign exchange counters, national debts, privatization versus nationalization of the healthcare services and the government's transparency in the healthcare administration do play a significant role to ease the costburden of the medical tourists. The currently available public domain data are too insufficient to configure the "landscape" of the medical tourism. However, it is worthwhile to understand the economic ramifications due to medical tourism.

\section{REFERENCES}

Garg, R., 2013. "All is not well” with medical tourism. Indian J. Community Med., 38: 59-61. DOI: 10.4103/0970-0218.106631

Giudici, P. and S. Figini, 2009. Applied Data Mining for Business and Industry. 2nd Edn., Wiley, Chichester, Hoboken, ISBN-10: 9780470058862, pp: 249.

Hopkins, L., Labonte, R., Runnels, V. and Packer, C., 2012. Medical tourism today: What is the state of existing knowledge. J. Public Health Policy, 31: 185-198. DOI: 10.1057/jphp.2010.10

Johnston, R., V.A. Crooks, J. Snyder and P. Kingsbury, 2010. What is known about the effects of medical tourism in destination and departure countries? A scoping review. Int. J. Equity Health, 9: 24-24. DOI: 10.1186/1475-9276-9-24

Jose, R. and S. Sachdeva, 2010. Keeping an eye on future: Medical tourism. Indian J. Community Med., 35: 376-378. DOI: 10.4103/0970-0218.69247

Malchesky, P.S., 2011. Organ replacement, medical device costs and medical tourism: Globalization of the clinical application of artificial organ technologies? Artif. Organs, 35: 1139-1141. DOI: 10.1111/j.1525-1594.2011.01396.x

Mason, A. and K.B. Wright, 2011. Framing medical tourism: An examination of appeal, risk, convalescence, accreditation and interactivity in medical tourism web sites. J. Health Commun., 16: 163-177. DOI: 10.1080/10810730.2010.535105 
Ramalingam Shanmugam / International Journal of Research in Nursing 3 (2) (2012) 38-47

NaRanong, A. and V. NaRanong, 2011. The effects of medical tourism: Thailand's experience. Bull World Health Organ., 89: 336-344. DOI: 10.2471/BLT.09.072249

Niechajev, I. and J. Frame, 2012. A plea to control medical tourism. Aesth Plast Surgery, 36: 202-206. DOI: 10.1007/s00266-011-9766-0

Samir, N. and S. Karim, 2011. An insight: Medical tourism, local and international perspective. Oman Med. J., 26: 215-218. DOI: 10.5001/omj.2001.54

Solomon, H., 2011. Affective journeys: The emotional structuring of medical tourism in India. Anthropol. Med., $\quad 18$ : $\quad 105-118 . \quad$ DOI: $10.1080 / 13648470.2010 .525878$
Turner, L., 2010. "Medical tourism" and the global marketplace in health services: U.S. patients, international hospitals and the search for affordable health care. Globalization Med. Care, 40: 443-467. PMID: 20799670

Underwood, H.R. and H.J. Makadon, 2010. Medical tourism: Game-changing innovation or passing fad? Healthcare Financial Manage., 64: 112-114. PMID: 20831004 